\title{
Effects of increasing docosahexaenoic acid intake in human healthy volunteers on lymphocyte activation and monocyte apoptosis
}

\author{
Saïda Mebarek ${ }^{1,2,3,4,5}$, Natalia Ermak ${ }^{6,7}$, Amal Benzaria ${ }^{1,2,3,4,5}$, Stéphanie Vicca ${ }^{7,8}$, Madeleine Dubois ${ }^{1,2,3,4,5}$, \\ Georges Némoz ${ }^{1,2,3,4,5}$, Martine Laville ${ }^{1,2,3,4,5}$, Bernard Lacour ${ }^{6,7}$, Evelyne Véricel ${ }^{1,2,3,4,5}$, \\ Michel Lagarde ${ }^{1,2,3,4,5}$ and Annie-France Prigent ${ }^{1,2,3,4,5 *}$ \\ ${ }^{1}$ INSERM U870, INSA-Lyon, 11 avenue Jean Capelle, Bât. Louis Pasteur, 69621 Villeurbanne Cedex, France \\ ${ }^{2}$ INSA-Lyon, RMND, F-69621 Villeurbanne, France \\ ${ }^{3}$ INRA, UMR1235, F-69600 Oullins, France \\ ${ }^{4}$ Université Lyon 1, Faculté de Médecine Lyon-Sud, F-69600 Oullins, France \\ ${ }^{5}$ Hospices Civils de Lyon (Service de Diabétologie et Nutrition, Hôpital Edouard Herriot), F-69008 Lyon, France \\ ${ }^{6}$ Université Paris-Sud 11,UMR-1154, Faculté de Pharmacie, F-92296 Châtenay-Malabry, France \\ ${ }^{7}$ Laboratoire de Biochimie A, Hôpital Necker, F-75730 Paris, France \\ ${ }^{8}$ INSERM U845, Hôpital Necker, F-75730 Paris, France
}

(Received 31 March 2008 - Revised 12 June 2008 - Accepted 19 June 2008 - First published online 19 August 2008)

Dietary intake of long-chain $n$-3 PUFA has been reported to decrease several markers of lymphocyte activation and modulate monocyte susceptibility to apoptosis. However, most human studies examined the combined effect of DHA and EPA using relatively high daily amounts of $n$ - 3 PUFA. The present study investigated the effects of increasing doses of DHA added to the regular diet of human healthy volunteers on lymphocyte response to tetradecanoylphorbol acetate plus ionomycin activation, and on monocyte apoptosis induced by oxidized LDL. Eight subjects were supplemented with increasing daily doses of DHA $(200,400,800,1600 \mathrm{mg})$ in a TAG form containing DHA as the only PUFA, for 2 weeks each dose. DHA intake dose-dependently increased the proportion of DHA in mononuclear cell phospholipids, the augmentation being significant after $400 \mathrm{mg}$ DHA/d. The tetradecanoylphorbol acetate plus ionomycin-stimulated IL-2 mRNA level started to increase after ingestion of $400 \mathrm{mg}$ $\mathrm{DHA} / \mathrm{d}$, with a maximum after $800 \mathrm{mg}$ intake, and was positively correlated $(P<0.003)$ with DHA enrichment in cell phospholipids. The treatment of monocytes by oxidized LDL before DHA supplementation drastically reduced mitochondrial membrane potential as compared with native LDL treatment. Oxidized LDL apoptotic effect was significantly attenuated after $400 \mathrm{mg}$ DHA/d and the protective effect was maintained throughout the experiment, although to a lesser extent at higher doses. The present results show that supplementation of the human diet with low DHA dosages improves lymphocyte activability. It also increases monocyte resistance to oxidized LDL-induced apoptosis, which may be beneficial in the prevention of atherosclerosis.

DHA enrichment: Interleukin-2: Mitochondrial membrane potential: Oxidized LDL

Several human studies have shown that ingesting long-chain $n$-3 PUFA decreases some markers of immune function including lymphocyte proliferative responses and cytokine production $^{(1)}$. This immunosuppressive effect was especially observed with aged people ${ }^{(2,3)}$. However, studies conducted with younger people suggest that healthy adults are relatively insensitive to immunomodulation with long-chain $n$-3 PUFA $^{(4)}$. Another concern is that most studies examined the combined effects of DHA and EPA both present in different proportions depending on the source of fish oil administered to the volunteers. Only a few human studies examined the effects of either EPA or DHA separately on immune function. In the study of Kew et al. ${ }^{(5)}$ examining the effect of dietary supplementation of healthy middle-age subjects with $4.7 \mathrm{~g}$
EPA/d or $4.9 \mathrm{~g} \mathrm{DHA} / \mathrm{d}$, it was shown that only DHA, but not EPA, decreased the expression of CD69, an early marker of lymphocyte activation. These results are at variance with those of Thies et al. ${ }^{(6)}$ showing that fish oil, but not highly purified DHA, suppressed lymphocyte proliferation, or with those of Kelley et al. ${ }^{(7)}$ showing that consuming $6 \mathrm{~g}$ DHA/d for 3 months did not alter lymphocyte proliferation. Other studies have even reported quite opposite results. Thus, Schauder et al. ${ }^{(8)}$ reported that patients fed on parenteral nutrition supplemented with DHA-enriched fish oil during the postoperative period produced higher levels of IL-2 than those supplemented with soyabean oil or unsupplemented patients. The supplementation of healthy volunteers' diet with DHA-enriched oil providing $1.62 \mathrm{~g} \mathrm{DHA} / \mathrm{d}$ and

Abbreviations: oxLDL, oxidized LDL; PBM, peripheral blood monocyte; PBMC, peripheral blood mononuclear cell; $\Delta \psi \mathrm{\psi m}$, mitochondrial membrane potential. * Corresponding author: Dr Annie-France Prigent, INSERM U870, fax +334724385 24, email annie-france.prigent@insa-lyon.fr 
$0.78 \mathrm{~g} \mathrm{EPA} / \mathrm{d}$ for 2 months has recently been shown to increase concanavalin A-dependent lymphocyte proliferative responses and IL-10, interferon- $\gamma$ and TNF $\alpha$ production as compared with levels measured before supplementation ${ }^{(9)}$.

The reported effects of DHA and EPA on apoptosis have ranged from inhibition to stimulation, depending on the cell model used. It is generally believed that long-chain $n-3$ PUFA increase the rate of apoptosis of tumour cells, both in vitro when added to cell culture medium, and in tumour-bearing rodents fed DHA- or EPA-enriched diets ${ }^{(10)}$. However, a large variability has been observed in normal cell models including monocytes or monocytic cell lines. Thus, Sweeney et al. ${ }^{(11)}$ have recently shown that the treatment of monocytes purified from human umbilical cord blood with DHA or EPA induced a rapid and dose-dependent cell death, due to a loss of mitochondrial membrane potential. In contrast, the preincubation of U937 monocytic cells with DHA has been shown to attenuate apoptosis induced by stimulation with $\mathrm{TNF} \alpha$ in the presence or absence of cycloheximide, this antiapoptotic effect being accompanied by an enrichment of DHA in membrane phospholipids ${ }^{(12)}$. However, to our knowledge, the influence of DHA supplementation of the human diet on ex vivo monocyte susceptibility to proapoptotic stimuli has never been investigated.

In the present study we sought to examine the effects of increasing doses of DHA added to the regular diet of human healthy volunteers on some aspects of immune function. We chose to evaluate IL-2 mRNA expression in response to phorbol ester and ionomycin activation as a marker of lymphocyte ex vivo activation and to measure changes in mitochondrial membrane potential induced by oxidized LDL (oxLDL) as a marker of monocyte susceptibility to apoptosis. Results were examined in regard to changes in the fatty acid composition of mononuclear cell phospholipids.

\section{Subjects and methods}

\section{Subjects and experimental design}

The eight subjects recruited for the study were healthy male volunteers aged between 53 and 65 years (mean 58.7 years). Each of them gave informed consent and the study was approved by the 'Comité consultatif de protection des personnes dans la recherche biomédicale de Lyon A'. At the beginning of the study each of them had normal blood cell counts, cholesterol (5.47 (SE 0.20) mmol/l), TAG (1.76 (SE 0.4) $\mathrm{mmol} / \mathrm{l}$ ) and glucose (5.25 (SE 0.2) mmol/l) blood levels. They ingested successively 200, 400, 800, $1600 \mathrm{mg}$ DHA in a TAG form per day, for 2 weeks each dose without interruption. DHA supplement was administered in soft gelatine capsules that each contained $200 \mathrm{mg}$ DHA and $0.125 \mathrm{mg}$ DL-tocopherol plus $0.125 \mathrm{mg}$ ascorbyl palmitate (Pro-Mind Forte; Decola Neutraceutics, Maldegem, Belgium). The fatty acid composition of the TAG was: $22: 6 n-3,40 \%$; $18: 2 n-6,1.2 \%$; total MUFA, $22.2 \%$ (including $18: 1 n-9$, $20 \cdot 2 \%+16: 1 n-7,2 \%$ ); total SFA, $36 \cdot 6 \%$ (including $16: 0$, $14 \%+14: 0,16 \%+12: 0,6 \cdot 6 \%$ ). Blood samples were collected after overnight fasting before DHA supplementation and after each DHA dose, and mononuclear cells were isolated. Blood samples were also collected 5 weeks after supplementation was arrested. The fatty acid composition of cell phospholipids was analysed and cell functions were evaluated. Each individual was asked not to deviate from regular habits during the study period and not to take any drugs at least $10 \mathrm{~d}$ before the initial blood sampling and during the test period.

\section{Peripheral blood mononuclear cell and monocyte isolation}

Venous blood was drawn into ACD anticoagulant. Peripheral blood mononuclear cells (PBMC) were separated by dextran sedimentation and density gradient centrifugation through Histopaque 1077 and then washed three times with RPMI 1640 by low-speed centrifugation in order to more thoroughly eliminate the contaminating platelets. PBMC were then adjusted to a concentration of $2 \times 10^{7}$ cells/ml in RPMI 1640 (with HEPES and bicarbonate) medium. All steps were carried out at room temperature. Under such conditions cell viability, established by the trypan blue exclusion test, was always greater than $95 \%$. Mononuclear cell suspensions were used to evaluate IL-2 expression and to determine the fatty acid composition of phospholipids. An aliquot of this cell suspension was used for monocyte isolation. Peripheral blood monocytes (PBM) were isolated from mononuclear cell suspensions by adherence $(1 \mathrm{~h})$. After non-adherent cells were discarded, PBM $\left(10^{6} / \mathrm{ml}\right)$ were incubated in RPMI medium supplemented as previously described ${ }^{(13)}$ and were cultured in the presence of native LDL or oxLDL for $4 \mathrm{~h}$. PBM preparations were analysed by flow cytometry using CD14 monoclonal antibody (BD Biosciences, Heildelberg, Germany) and isotype control IgG1 (Serotec, Düsseldorf, Germany) as a negative control. At least $70 \%$ of PBM were CD14 + (not shown).

\section{Peripheral blood mononuclear cell treatment, RNA isolation and semi-quantitative RT-PCR analyses}

Mononuclear cells suspended at a concentration of $10^{6}$ cells/ $\mathrm{ml}$ in RPMI were incubated with $200 \mathrm{nmol} / \mathrm{l}$ tetradecanoylphorbol acetate and $500 \mathrm{nmol} / 1$ ionomycin for $2 \mathrm{~h}$ at $37^{\circ} \mathrm{C}$ in an air- $-\mathrm{CO}_{2}$ (95:5) atmosphere. At the end of the incubation period, total RNA was isolated from control and tetradecanoylphorbol acetate-treated cells using Tri Reagent according to the manufacturer's instructions. The sense and antisense primers for the amplification of IL- 2 were $5^{\prime}$-CACTAAGTCTTGCACTTGTCAC-3' and 5'-CCTTCTTGGGCATGTAAAACT- $3^{\prime}$, respectively (expected size of amplified fragment $186 \mathrm{bp}$ ). $\beta$-Actin primers were used as internal control to normalize the data. RT-PCR were performed on $2 \mu \mathrm{g}$ RNA for IL-2 and $1 \mu \mathrm{g}$ RNA for $\beta$-actin using QIAGEN ${ }^{\circledR}$ OneStep RT-PCR kit (Courtaboeuf, France) according to the manufacturer's instructions. Reaction products were resolved by electrophoresis on $1 \%$ agarose gel impregnated with ethidium bromide, and visualized by UV transillumination.

Fatty acid composition of peripheral blood mononuclear cell phospholipids

Diheptadecanoyl phosphatidylcholine $(20 \mu \mathrm{g})$ as an internal standard was added to $1 \mathrm{ml}$ mononuclear cell suspension. The cell suspensions were then extracted according to Bligh \& Dyer ${ }^{(14)}$ and cell lipid extracts were separated on silica gel G60 plates (Merck, Darmstadt, Germany) with the solvent 
system hexane-diethyl ether-acetic acid (60:40:1, by vol.). The silica gel areas corresponding to phospholipids were scraped off and transmethylated according to Bowyer et al. ${ }^{(15)}$ as previously described ${ }^{(3)}$. Briefly, one volume of $5 \% \mathrm{H}_{2} \mathrm{SO}_{4}$ in methanol was added to the scraped silica gel and transmethylation was carried out at $100^{\circ} \mathrm{C}$ for $90 \mathrm{~min}$ in screw-capped tubes. The reaction was terminated by the addition of 1.5 volumes of ice-cold $5 \%$ (w/v) $\mathrm{K}_{2} \mathrm{CO}_{3}$, and the fatty acid methyl esters were extracted with isooctane and resolved by GC using a Hewlett Packard chromatograph HP 6890 model, equipped with a capillary column $(60 \mathrm{~m} \times 0.25 \mathrm{~mm}$, BPx70 SGE; Bellfonte, USA) and flame ionization detection. The column was two-step programmed from 135 to $160^{\circ} \mathrm{C}$ at $2^{\circ} \mathrm{C} / \mathrm{min}$ and from 160 to $205^{\circ} \mathrm{C}$ at $1.5^{\circ} \mathrm{C} / \mathrm{min}$; the detection temperature was maintained at $250^{\circ} \mathrm{C}$. The vector gas was helium at a pressure of $0.8 \mathrm{psi}$ $(5 \cdot 52 \mathrm{kPa})$. Fatty acid methyl esters were identified by their retention time relative to standards.

\section{LDL isolation and oxidation}

LDL fraction was isolated from human plasma by sequential ultracentrifugation $^{(16)}$. LDL $(1 \mathrm{mg} / \mathrm{ml})$ oxidation was induced for $30 \mathrm{~min}$ at $37^{\circ} \mathrm{C}$ with $4 \mathrm{mmol} / \mathrm{l} \mathrm{HOCl}$ (corresponding to oxidant:protein molar ratio of 2000:1). Untreated LDL and oxLDL were dialysed overnight against isotonic PBS. Native LDL and oxLDL were used at a cholesterol concentration of $200 \mu \mathrm{g} / \mathrm{ml}$ in the incubation medium. The lipid peroxide content of native LDL and oxLDL was determined by analysing thiobarbituric acid-reactive substances and expressed as malondialdehyde equivalents ${ }^{(17)}$. As compared to previous results obtained after copper treatment of native LDL, malondialdehyde was generated at a lower extent in $\mathrm{HOCl}-$ oxLDL than in copper-oxLDL $(0.68 \mathrm{nmol}$ malondialdehyde $/ \mathrm{mg}$ protein for $\mathrm{HOCl}$-oxLDL $v \cdot 0 \cdot 10$ for native $\mathrm{LDL}$ and $4 \cdot 20$ for copper-oxLDL $\left.{ }^{(18)}\right)$.

The degree of oxidation was quantified by an increased relative mobility on $0.6 \%$ agarose gels ${ }^{(19)}$, indicating an enhanced negative charge of $\mathrm{HOCl}-$ oxLDL. The relative mobility of $\mathrm{HOCl}-\mathrm{oxLDL}$ on agarose gels as an index for lipoprotein oxidation was $2 \cdot 5-3 \cdot 0$ compared with that of native LDL.

\section{Analysis of mitochondrial membrane potential}

Following individual incubations, cells were loaded with the fluorochrome 3,3'-dihexyloxacarbocyanine iodide (Molecular Probes Inc., Eugene, OR, USA), used at $40 \mathrm{nmol} / \mathrm{l}$ final concentration for $30 \mathrm{~min}$. The dye accumulates in mitochondria that contain an intact mitochondrial membrane potential $(\Delta \psi \mathrm{m})$, and the fluorescence of $3,3^{\prime}$-dihexyloxacarbocyanine iodide can therefore be considered as an indicator of the relative mitochondrial membrane polarization state ${ }^{(20)}$. Relative fluorescence intensities were measured on a FACScan flow cytometer.

\section{Statistical analysis}

Data expressed as means and their standard errors were analysed by ANOVA and means were compared by a protected $t$ test. Correlations between changes in parameters induced by DHA were tested by linear regression. $P<0.05$ was considered significant.

\section{Results and discussion}

DHA supplement was well tolerated throughout the study. No significant variations in systolic and diastolic blood pressure, glucose and TAG blood concentrations were observed before and after DHA supplementation. DHA treatment was associated with a slight but significant increase in HDL-cholesterol (1.43 (SE 0.090) v. 1.60 (SE 0.12) mmol/l, + $11.9 \%$, $P<0.05)$ and a trend of LDL-cholesterol to increase (3.23 (SE 0.24) v. $3.56(\mathrm{SE} 0.27) \mathrm{mmol} / \mathrm{l},+10.2 \%$, NS) after ingestion of the highest dose of DHA $(1600 \mathrm{mg} / \mathrm{d})$. Interestingly, the HDL-cholesterol to LDL-cholesterol ratio remained unchanged throughout the study. The present results are in partial agreement with those of a recent study ${ }^{(21)}$ reporting an increase of both HDL- and LDL-cholesterol after ingestion of $3 \mathrm{~g} / \mathrm{d}$ DHA for $90 \mathrm{~d}$. However, at variance with the present results, in the study of Kelley et al. ${ }^{(21)}$ only LDL-cholesterol changes were significant.

DHA intake significantly increased the proportion of DHA in mononuclear cell phospholipids (Table 1; Fig. 1), starting from the second dose of $400 \mathrm{mg} / \mathrm{d}(+25 \%$ as compared with level measured before DHA intake). DHA incorporation linearly increased $\left(R^{2} 0.99, P<0.003\right)$ as a function of DHA doses up to $800 \mathrm{mg} / \mathrm{d}$ dose, and slowed down thereafter. The increase in DHA proportion reached $+76 \%$ with respect to baseline $(5.67(\operatorname{SE~0.26)~v.~} 3.22$ (SE 0.28) at baseline) after the highest dose of $1600 \mathrm{mg} / \mathrm{d}$. Although several studies have reported that supplementation of the diet with $n$ - 3 fatty acids results in an increased $n-3$ fatty acid content of $\operatorname{PBMC}^{(3,6)}$, only a few studies have examined $n-3$ fatty acid incorporation in PBMC phospholipids as a function of the ingested dose. In a recent study, Rees et al. ${ }^{(22)}$ have shown that EPA was incorporated in a linear dose-response fashion into PBMC phospholipids following ingestion of EPA doses ranging from 1.35 to $4.05 \mathrm{~g} / \mathrm{d}$ provided as EPA-rich oil. However, to our knowledge the present study is the first one to describe a dose-response relationship between increased DHA intake and increased DHA incorporation in mononuclear cell phospholipids. After a 5-week washout period, DHA proportion no longer differed from that measured before DHA supplementation (Table 1). Although the algal oil used in the present study was totally devoid of EPA, the proportion of EPA in mononuclear cell phospholipids was also increased, the rise being significant only after ingestion of the third and fourth DHA doses (0.38 (SE 0.06) at baseline $v$. 0.60 (SE 0.07) and 0.61 (SE 0.07) after 800 and $1600 \mathrm{mg} \mathrm{DHA} / \mathrm{d}$, respectively). The present result suggests that DHA was efficiently retroconverted to EPA and increased in blood mononuclear cells as previously observed $^{(23,24)}$. These modifications were accompanied by decreased proportions of long-chain $n-6$ fatty acids, specifically arachidonic acid (20:4n-6) and adrenic acid (22:4n-6). Surprisingly, the proportion of $22: 5 n-3$ was also significantly lowered by DHA treatment, the decrease being significant from the dose of $200 \mathrm{mg} / \mathrm{d}$. Such a decrease in $22: 5 n-3$ concentration has already been reported in serum phospholipids of women supplemented with $2.8 \mathrm{~g} \mathrm{DHA} / \mathrm{d}$ for $28 \mathrm{~d}^{(24)}$ or in erythrocyte phospholipids of middle-aged people supplemented with $0.7 \mathrm{~g}$ DHA/d for 3 months ${ }^{(25)}$. This is likely a result of DHA competition for esterification at the $s n-2$ position of glycerophospholipids. 
Table 1. Fatty acid composition of mononuclear cell phospholipids ( $\mathrm{mol} / 100 \mathrm{~mol}$ total fatty acids) at baseline (0) and after supplementation with increasing doses of $\mathrm{DHA}^{*}$

(Mean values with their standard errors for eight subjects)

\begin{tabular}{|c|c|c|c|c|c|c|c|c|c|c|c|c|}
\hline \multirow[b]{3}{*}{ Fatty acids } & \multicolumn{12}{|c|}{ Daily DHA dose $(\mathrm{mg})$} \\
\hline & \multicolumn{2}{|c|}{0} & \multicolumn{2}{|c|}{200} & \multicolumn{2}{|c|}{400} & \multicolumn{2}{|c|}{800} & \multicolumn{2}{|c|}{1600} & \multicolumn{2}{|c|}{ Washout } \\
\hline & Mean & SE & Mean & SE & Mean & SE & Mean & SE & Mean & SE & Mean & SE \\
\hline $4: 0$ & $0 \cdot 10^{\mathrm{a}}$ & 0.04 & $0 \cdot 16^{a, b}$ & 0.04 & $0.23^{b, c}$ & 0.03 & $0 \cdot 26^{c}$ & 0.26 & $0.22^{b, c}$ & 0.02 & $0.20^{a, b, c}$ & 0.04 \\
\hline $6: 0$ & $21 \cdot 45^{a, b}$ & 0.39 & $18 \cdot 80^{a}$ & 2.43 & $22 \cdot 87^{\mathrm{b}}$ & 0.32 & $22 \cdot 25^{\mathrm{b}}$ & 0.63 & $22 \cdot 08^{a, b}$ & 0.76 & $22 \cdot 42^{\mathrm{b}}$ & $1 \cdot 12$ \\
\hline $16: 1 n-9$ & $0.04^{\mathrm{a}}$ & 0.03 & $0 \cdot 12^{a, b}$ & 0.04 & $0 \cdot 13^{a, b}$ & 0.03 & $0.2^{\mathrm{b}}$ & 0.04 & $0.18^{b}$ & 0.05 & $0.18^{\mathrm{b}}$ & 0.02 \\
\hline $16: 1 n-7$ & $0.14^{\mathrm{a}}$ & 0.06 & $0.22^{a, b}$ & 0.06 & $0.28^{\mathrm{b}}$ & 0.02 & $0.28^{b}$ & 0.03 & $0.25^{a, b}$ & 0.03 & $0.29^{b}$ & 0.03 \\
\hline 18:0 & $22 \cdot 10^{\mathrm{a}, \mathrm{b}}$ & 0.40 & $21.63^{a}$ & 0.30 & $22 \cdot 13^{\mathrm{a}, \mathrm{b}}$ & 0.32 & $22 \cdot 08^{\mathrm{a}, \mathrm{c}}$ & 0.47 & $23 \cdot 21^{\mathrm{b}}$ & 0.47 & $23.07^{b, c}$ & 0.56 \\
\hline $18: 1 n-9$ & $11 \cdot 60^{\mathrm{a}}$ & 0.75 & $13 \cdot 25$ & 0.97 & 13.45 & 0.56 & $12 \cdot 83$ & 0.45 & $12 \cdot 83$ & 0.47 & $14 \cdot 83^{b}$ & 1.44 \\
\hline $18: 1 n-7$ & $2 \cdot 78^{a}$ & 0.30 & $2 \cdot 37^{a, b}$ & 0.36 & $2 \cdot 04^{b}$ & 0.13 & $2 \cdot 14^{\mathrm{b}}$ & 0.09 & $2 \cdot 03^{\mathrm{b}}$ & 0.09 & $2 \cdot 04^{b}$ & 0.14 \\
\hline $18: 2 n-6$ & 8.03 & 0.17 & 8.02 & 0.32 & 8.41 & 0.37 & $8 \cdot 36$ & 0.37 & $8 \cdot 72$ & 0.44 & 7.95 & 0.33 \\
\hline $20: 2 n-6$ & 0.61 & 0.02 & 0.63 & 0.05 & 0.65 & 0.06 & 0.58 & 0.05 & 0.59 & 0.05 & 0.56 & 0.05 \\
\hline $20: 3 n-6$ & 2.02 & 0.11 & $2 \cdot 12$ & 0.10 & 2.02 & 0.10 & 1.98 & 0.12 & 1.93 & 0.12 & 1.95 & 0.09 \\
\hline $20: 4 n-6$ & $21 \cdot 18^{a}$ & 0.36 & $20 \cdot 84^{a}$ & 0.44 & $19 \cdot 21^{\mathrm{b}}$ & 0.41 & $19 \cdot 44^{\mathrm{b}}$ & 0.37 & $18 \cdot 28^{\mathrm{b}}$ & 0.56 & $18 \cdot 38^{\mathrm{b}}$ & 0.56 \\
\hline $20: 5 n-3$ & $0.38^{\mathrm{a}}$ & 0.06 & $0.52^{a, b}$ & 0.03 & $0.46^{a, b}$ & 0.06 & $0.60^{\mathrm{b}}$ & 0.07 & $0.61^{\mathrm{b}}$ & 0.07 & $0.55^{a, b}$ & 0.10 \\
\hline $2: 4 n-6$ & $3 \cdot 70^{\mathrm{a}}$ & 0.47 & $2 \cdot 86^{\mathrm{b}}$ & 0.41 & $1.98^{\mathrm{C}}$ & 0.11 & $1.77^{c}$ & 0.11 & $1.46^{\mathrm{c}}$ & 0.09 & $1.98^{\mathrm{C}}$ & 0.13 \\
\hline $22: 5 n-3$ & $2 \cdot 65^{\mathrm{a}}$ & 0.06 & $2 \cdot 35^{\mathrm{b}}$ & 0.14 & $1.96^{\mathrm{c}}$ & 0.10 & $1.84^{\mathrm{C}}$ & 0.11 & $1.41^{\mathrm{d}}$ & 0.08 & $2 \cdot 08^{b, c}$ & 0.13 \\
\hline $22: 6 n-3$ & $3 \cdot 22^{a}$ & 0.28 & $3 \cdot 64^{a, b}$ & 0.22 & $4.01^{\mathrm{b}}$ & 0.26 & $5.08^{\mathrm{C}}$ & 0.26 & $5 \cdot 67^{c}$ & 0.26 & $3.06^{a, d}$ & 0.21 \\
\hline SFA & $42 \cdot 84^{\mathrm{a}}$ & 0.32 & $43 \cdot 08^{a, b}$ & 0.43 & $45 \cdot 23^{a, c}$ & 0.44 & $44.58^{a, c}$ & 0.65 & $45 \cdot 51^{\mathrm{b}, \mathrm{c}}$ & 1.20 & $45 \cdot 68^{c}$ & 1.61 \\
\hline MUFA & $15 \cdot 21$ & 0.72 & $15 \cdot 96$ & 0.78 & 15.96 & 0.49 & $15 \cdot 63$ & 0.51 & 15.47 & 0.54 & 17.51 & 1.42 \\
\hline$n-6$ PUFA & $35.38^{\mathrm{a}}$ & 0.76 & $34.46^{\mathrm{a}, \mathrm{b}}$ & 0.59 & $32 \cdot 38^{\mathrm{c}}$ & 0.56 & $32 \cdot 27^{c}$ & 0.53 & $31.31^{c}$ & 0.70 & $31 \cdot 12^{c}$ & 0.82 \\
\hline n-3 PUFA & $6.59^{a}$ & 0.41 & $6 \cdot 50^{a, b}$ & 0.21 & $6 \cdot 43^{a, b}$ & 0.31 & $7 \cdot 52^{c}$ & 0.31 & $7 \cdot 72^{\mathrm{c}}$ & 0.37 & $5.69^{a, d}$ & 0.31 \\
\hline$n-6: n-3$ PUFA & $5 \cdot 52^{\mathrm{a}}$ & 0.36 & $5 \cdot 34^{a, b}$ & 0.19 & $5 \cdot 13^{a, b}$ & 0.27 & $4.33^{c}$ & 0.16 & $4 \cdot 11^{\mathrm{C}}$ & 0.17 & $5 \cdot 46^{a, d}$ & 0.34 \\
\hline
\end{tabular}

${ }^{a-d}$ Mean values within a row with unlike superscript letters were significantly different $(P<0.05)$. Data were analysed by ANOVA and means were compared by a protected $t$ test.

${ }^{*}$ For details of procedures, see Subjects and methods.

An early response of lymphocytes to activation by phorbol ester and ionomycin is the expression of IL-2 mRNA, which starts after $1 \mathrm{~h}$ of treatment and reaches a maximum after $2 \mathrm{~h}$ of stimulation ${ }^{(26,27)}$. Thus, we examined by RT-PCR IL-2 mRNA expression after $2 \mathrm{~h}$ of tetradecanoylphorbol acetate and ionomycin treatment of mononuclear cells before DHA ingestion and after each dose intake. In the absence of activators, the basal IL-2 mRNA expression remained very low and unaffected by DHA supplementation (Fig. 2). In contrast, the

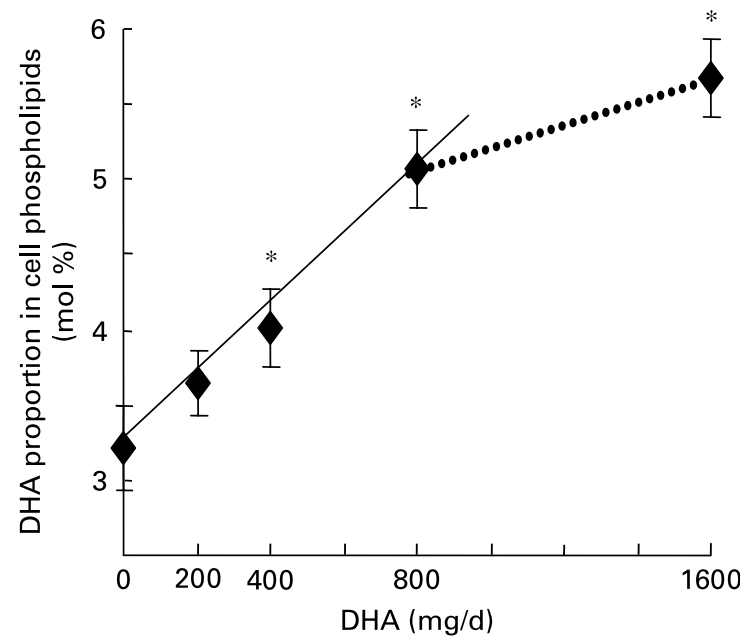

Fig. 1. Change in DHA proportion in mononuclear cell phospholipids during supplementation with different doses of DHA-rich oil $\left(-, R^{2} 0.99 ; P<0.003\right)$. , Non-linear. Values are means with their standard errors depicted by vertical bars $(n 8)$. *Mean values were significantly different from those at baseline $(P<0.05)$. stimulated mRNA level started to increase after ingestion of $400 \mathrm{mg}$ DHA/d, peaked after the dose of $800 \mathrm{mg} / \mathrm{d}$ and remained elevated after ingestion of the highest DHA dose. After the 5-week washout period, the stimulated level of mRNA expression returned to values observed before the

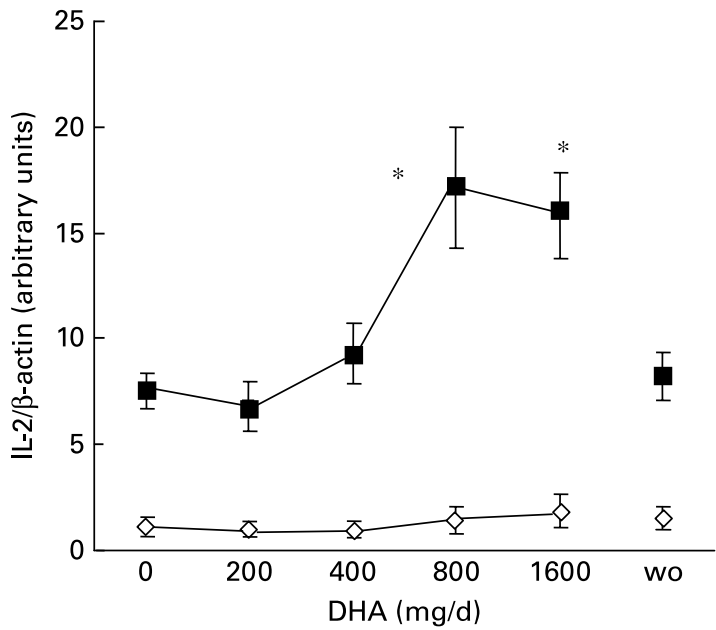

Fig. 2. Effect of increasing DHA intake on IL-2 mRNA expression in mononuclear cells. Peripheral blood mononuclear cells suspended at a concentration of $10^{6}$ cells $/ \mathrm{ml}$ in RPMl were incubated with $200 \mathrm{nmol} / \mathrm{l}$ tetradecanoylphorbol acetate (TPA) and $500 \mathrm{nmol} / \mathrm{l}$ ionomycin for $2 \mathrm{~h}$ at $37^{\circ} \mathrm{C}$. At the end of the incubation period, total RNA was isolated from control $(\diamond)$ and TPA-treated cells ( $\mathbf{\square})$, and submitted to RT-PCR. Amounts of IL-2 amplification products were normalized by the amounts of $\beta$-actin amplification products. Ratio values are expressed relative to IL-2/ $\beta$-actin ratio of unstimulated cells at baseline taken as 1 . Values are means with their standard errors depicted by vertical bars $(n 8)$. Mean values were significantly different from those at baseline: ${ }^{\star} P<0.05$. wo, Washout. 
supplementation period, as did DHA proportion in cell phospholipids. Interestingly, the stimulated mRNA level of IL-2 was positively correlated with DHA enrichment in cell phospholipids (Fig. 3). The present results indicate that a moderate DHA intake does not decrease, but rather enhances, IL-2 mRNA expression in lymphocytes from healthy middle-aged volunteers, thus suggesting an improvement of their activability. This is in agreement with recent reports showing that $n-3$ fatty acids may have different effects on immune function depending on the age and health status of the subjects ${ }^{(4,28)}$. Because tetradecanoylphorbol acetate plus ionomycin-induced signals bypass cell membrane receptors, modifications of membrane fluidity or lipid rafts are probably not involved. An alternative mechanism might be a specific effect of DHA or metabolites on the regulation of expression of key lymphocyte genes $^{(9)}$.

In a previous study ${ }^{(18)}$, we showed that $\mathrm{HOCl}-\mathrm{oxLDL}$ was able to induce apoptosis of the human cultured U937 monocytic cell line in a concentration-dependent manner, via the mitochondrial apoptotic pathway. Based on this, we chose to expose human primary monocytes to a $\mathrm{HOCl}-\mathrm{oxLDL}$ concentration of $200 \mu \mathrm{g} / \mathrm{ml}$. As shown in Fig. 4, the treatment of monocytes freshly isolated from volunteers before DHA supplementation by oxLDL drastically reduced mitochondrial membrane potential, as compared with native LDL treatment (negative control). After DHA intake monocytes became more resistant to oxLDL toxic effect starting from the second DHA dose of $400 \mathrm{mg} / \mathrm{d}$ (62.8 (SE 1.8) \% of cells with $\Delta \psi \mathrm{m}$ disruption for oxLDL treatment and DHA $400 \mathrm{mg} / \mathrm{d} v$. 77.1 (SE 1.2) \% for oxLDL treatment before DHA supplementation). The protective effect of DHA supplementation was maintained throughout the experiment although it tended to decline after ingestion of the two highest DHA doses (68.3 (SE 2.0) and 69.3 (SE 1.8) \% of cells with low $\Delta \psi \mathrm{m}$ after 800 and $1600 \mathrm{mg}$ DHA/d). However, whatever the DHA doses ingested, oxLDL still induced monocyte mitochondrial membrane depolarization, which may promote apoptosis. At the present time, it is unclear whether apoptosis induced by various stimuli is harmful or beneficial in various physiological and pathological circumstances.

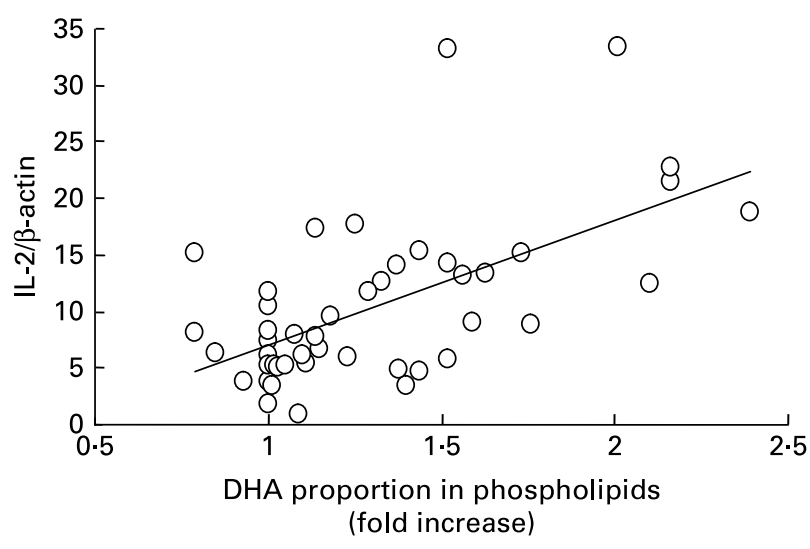

Fig. 3. Positive relationship between DHA enrichment in mononuclear cell phospholipids and IL-2 mRNA expression $\left(R^{2} 0.36 ; P<0.001\right)$. For each subject normalized IL-2/ $\beta$-actin ratio is plotted as a function of the relative DHA enrichment (with respect to baseline value taken as 1) in cell phospholipids.

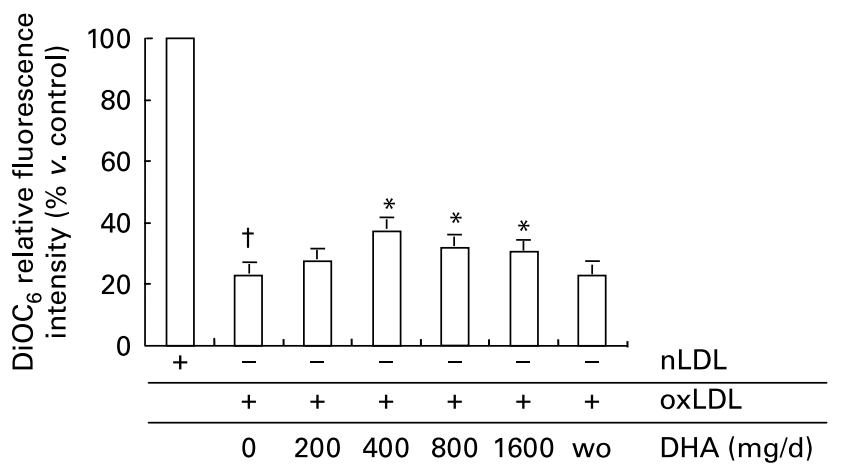

Fig. 4. Effect of increasing DHA intake on oxidized LDL (oxLDL)-treated monocyte mitochondrial membrane potential. Human monocytes were treated with $200 \mu \mathrm{g} / \mathrm{ml}$ native LDL (nLDL) or $200 \mu \mathrm{g} / \mathrm{ml}$ oxLDL for $4 \mathrm{~h}$ at $37^{\circ} \mathrm{C}$. Cells were then incubated for $30 \mathrm{~min}$ with $40 \mathrm{nmol} / / 3,3^{\prime}$-dihexyloxacarbocyanine iodide $\left(\mathrm{DiOC}_{6}\right)$ at $37^{\circ} \mathrm{C}$, and analysed by flow cytometry. Values are means with their standard errors depicted by vertical bars $(n 4)$. Mean values for oxLDL and DHA were significantly different from those of oxLDL only: ${ }^{\star} P<0.05$. Mean values were significantly different from those of $n L D L$ only: $\dagger P<0.0001$. wo, Washout.

Indeed, apoptosis of mature macrophage is thought to promote plaque destabilization and vessel occlusion in the late stages of atherosclerosis, whereas monocyte apoptosis may be beneficial in the initial stages of the atheromatous process ${ }^{(18)}$. After the washout period, the susceptibility of monocytes to oxLDL apoptosis was no longer different from that observed at baseline (oxLDL alone before DHA ingestion). Some nutritional studies have shown that LDL isolated from fish oil-supplemented volunteers, thus enriched in $n$ - 3 fatty acids, induced less apoptosis in U937 cells after oxidation compared to LDL isolated from sunflower oil-supplemented subjects ${ }^{(29,30)}$. On the other hand, the effects of $n-3$ fatty acid enrichment of monocyte phospholipids on susceptibility to apoptosis seem to be largely dependent on experimental conditions ${ }^{(11,12)}$. Thus, in umbilical cord monocytes the pro-apoptotic effect of DHA involved a loss of mitochondrial membrane potential accompanied by caspase- 3 activation ${ }^{(11)}$, whereas in the U937 monocytic cell line the anti-apoptotic effect of DHA was attributed to inhibition of cytosolic phospholipase A2 through esterification in cell phospholipids ${ }^{(12)}$.

Hypochlorous acid is known to preferentially modify the protein moiety of human LDL, but HOCl-modified LDL can in turn induce lipid peroxidation and antioxidant depletion as secondary events subsequent to amino acid modifications $^{(31)}$. Thus, we have recently shown that $\mathrm{HOCl}$-modified oxLDL induced the generation of reactive oxygen species in U937 monocytic cells ${ }^{(18)}$. Although highly susceptible to peroxidation, DHA may have antioxidant properties especially when used at low concentrations. This proposal is supported both by nutritional studies in man, and by studies involving in vitro DHA enrichment of different cell models. Indeed, Véricel et al. ${ }^{(32)}$ have shown a significant increase of $\alpha$ - and $\gamma$-tocopherol accompanied by a decrease in malondialdehyde in platelets of elderly people supplemented for 6 weeks with low doses of marine oil. Bechoua et al. ${ }^{(33)}$ have reported that low concentrations of DHA decrease malondialdheyde production induced by $\mathrm{H}_{2} \mathrm{O}_{2}$ in human mononuclear cells. Similarly, the pretreatment of RAW264 macrophages with DHA has been shown to prevent the accumulation of intracellular peroxides induced by interferon- $\gamma$ plus lipopolysaccharide in a dose-dependent manner by a 
mechanism involving up-regulation of intracellular glutathione level ${ }^{(34)}$. Finally, low doses of DHA have been shown to strengthen cellular antioxidant defences by increasing glutathione peroxidase activity/expression in various types of cells including platelets ${ }^{(35)}$, mononuclear cells ${ }^{(36)}$ or neuronal cells ${ }^{(37)}$. Thus, the antioxidant properties of low DHA doses might explain the antiapoptotic effects observed in monocytes. Furthermore, they could also explain the stimulating effects on lymphocytes as both prooxidant and antioxidant states are required sequentially during lymphocyte activation $^{(38)}$.

\section{Acknowledgements}

This work was supported by INSERM and a grant from the Groupe Lipides et Nutrition (GLN) (2005). The contribution of each author was as follows: S. M., N. E., A. B., M. D., performing experiments; S. V., G. N., B. L., A.-F. P., writing the manuscript; M. Laville, promotor, investigator, coordinator; E. V., M. Lagarde, A.-F. P., designing the study. All the authors have seen and approved the contents of the paper. All the authors state that there are no conflicts of interest and all adhere to the Committee on Publication Ethics guidelines on research and publication ethics.

\section{References}

1. Calder PC (2007) Immunomodulation by omega-3 fatty acids. Prostaglandins Leukot Essent Fatty Acids 77, 327-335.

2. Meydani SN, Endres S, Woods MM, Goldin BR, Soo C, Morrill-Labrode A, Dinarello CA \& Gorbach SL (1991) Oral (n-3) fatty acid supplementation suppresses cytokine production and lymphocyte proliferation: comparison between young and older women. J Nutr 121, 547-555.

3. Bechoua S, Dubois M, Vericel E, Chapuy P, Lagarde M \& Prigent AF (2003) Influence of very low dietary intake of marine oil on some functional aspects of immune cells in healthy elderly people. Br J Nutr 89, 523-531.

4. Sijben JW \& Calder PC (2007) Differential immunomodulation with long-chain $n$-3 PUFA in health and chronic disease. Proc Nutr Soc 66, 237-259.

5. Kew S, Mesa MD, Tricon S, Buckley R, Minihane AM \& Yaqoob P (2004) Effects of oils rich in eicosapentaenoic and docosahexaenoic acids on immune cell composition and function in healthy humans. Am J Clin Nutr 79, 674-681.

6. Thies F, Nebe-von-Caron G, Powell JR, Yaqoob P, Newsholme EA \& Calder PC (2001) Dietary supplementation with gammalinolenic acid or fish oil decreases T lymphocyte proliferation in healthy older humans. J Nutr 131, 1918-1927.

7. Kelley DS, Taylor PC, Nelson GJ \& Mackey BE (1998) Dietary docosahexaenoic acid and immunocompetence in young healthy men. Lipids 33, 559-566.

8. Schauder P, Röhn U, Schäfer G, Korff G \& Schenk HD (2002) Impact of fish oil enriched total parenteral nutrition on DNA synthesis, cytokine release and receptor expression by lymphocytes in the postoperative period. Br J Nutr 87, S103-S110.

9. Gorjão R, Verlengia R, Lima TM, et al. (2006) Effect of docosahexaenoic acid-rich fish oil supplementation on human leukocyte function. Clin Nutr 25, 923-938.

10. Field CJ \& Schley PD (2004) Evidence for potential mechanisms for the effect of conjugated linoleic acid on tumor metabolism and immune function: lessons from $n-3$ fatty acids. Am J Clin Nutr 79, 1190S-1198S.
11. Sweeney B, Puri P \& Reen DJ (2007) Induction and modulation of apoptosis in neonatal monocytes by polyunsaturated fatty acids. J Pediatr Surg 42, 620-628.

12. Yano M, Kishida E, Iwasaki M, Kojo S \& Masuzawa Y (2000) Docosahexaenoic acid and vitamin E can reduce human monocytic U937 cell apoptosis induced by tumor necrosis factor. J Nutr 130, 1095-1101.

13. Xu XP, Meisel SR, Ong JM, Kaul S, Cercek B, Rajavashisth TB, Sharifi B \& Shah PK (1999) Oxidized low-density lipoprotein regulates matrix metalloproteinase- 9 and its tissue inhibitor in human monocyte-derived macrophages. Circulation 99, 993-998.

14. Bligh EG \& Dyer WJ (1959) A rapid method of total lipid extraction and purification. Can J Biochem Physiol 37, 911-917.

15. Bowyer DE, Leat WM, Howard AN \& Gresham GA (1963) The determination of the fatty acid composition of serum lipids separated by thin-layer chromatography; and a comparison with column chromatography. Biochim Biophys Acta 70, 423-431.

16. Havel RJ, Eder HA \& Bragdon JH (1955) The distribution and chemical composition of ultracentrifugally separated lipoproteins in human serum. $J$ Clin Invest 34, 1345-1353.

17. Conti M, Morand PC, Levillain P \& Lemonnier A (1991) Improved fluorometric determination of malonaldehyde. Clin Chem 37, 1273-1275.

18. Ermak N, Lacour B, Drüeke TB \& Vicca S (2008) Role of reactive oxygen species and Bax in oxidized low density lipoprotein-induced apoptosis of human monocytes. Atherosclerosis (In the Press).

19. Lin KY, Pan JP, Yang DL, Huang KT, Chang MS, Ding PY \& Chiang AN (2001) Evidence for inhibition of low density lipoprotein oxidation and cholesterol accumulation by apolipoprotein H (beta2-glycoprotein I). Life Sci 69, 707-719.

20. Chen LB (1988) Mitochondrial membrane potential in living cells. Annu Rev Cell Biol 4, 155-181.

21. Kelley DS, Siegel D, Vemuri M \& Mackey BE (2007) Docosahexaenoic acid supplementation improves fasting and postprandial lipid profiles in hypertriglyceridemic men. Am J Clin Nutr 86, 324-333.

22. Rees D, Miles EA, Banerjee T, Wells SJ, Roynette CE, Wahle KW \& Calder PC (2006) Dose-related effects of eicosapentaenoic acid on innate immune function in healthy humans: a comparison of young and older men. Am J Clin Nutr 83, 331-342.

23. Joulain C, Guichardant M, Lagarde M \& Prigent AF (1995) Influence of polyunsaturated fatty acids on lipid metabolism in human blood mononuclear cells and early biochemical events associated with lymphocyte activation. J Lipid Mediat Cell Signal 11, 63-79.

24. Stark KD \& Holub BJ (2004) Differential eicosapentaenoic acid elevations and altered cardiovascular disease risk factor responses after supplementation with docosahexaenoic acid in postmenopausal women receiving and not receiving hormone replacement therapy. Am J Clin Nutr 79, 765-773.

25. Theobald HE, Goodall AH, Sattar N, Talbot DC, Chowienczyk PJ \& Sanders TA (2007) Low-dose docosahexaenoic acid lowers diastolic blood pressure in middle-aged men and women. J Nutr 137, 973-978.

26. Gaffen SL \& Liu KD (2004) Overview of interleukin-2 function, production and clinical applications. Cytokine 28, $109-123$.

27. Diaz O, Mébarek-Azzam S, Benzaria A, Dubois M, Lagarde M Némoz G \& Prigent AF (2005) Disruption of lipid rafts stimulates phospholipase $\mathrm{d}$ activity in human lymphocytes: implication in the regulation of immune function. $J$ Immunol 175, 8077-8086.

28. Miles EA, Banerjee T, Wells SJ \& Calder PC (2006) Limited effect of eicosapentaenoic acid on T-lymphocyte and natural 
killer cell numbers and functions in healthy young males. Nutrition 22, 512-519.

29. Wu T, Geigerman C, Lee YS \& Wander RC (2002) Enrichment of LDL with EPA and DHA decreased oxidized LDL-induced apoptosis in U937 cells. Lipids 37, 789-796.

30. Lee YS \& Wander RC (2005) Reduced effect on apoptosis of 4-hydroxyhexenal and oxidized LDL enriched with $n$-3 fatty acids from postmenopausal women. J Nutr Biochem 16, 213-221.

31. Malle E, Marsche G, Arnhold J \& Davies MJ (2006) Modification of low-density lipoprotein by myeloperoxidase-derived oxidants and reagent hypochlorous acid. Biochim Biophys Acta 1761, 392-415.

32. Véricel E, Calzada C, Chapuy P \& Lagarde M (1999) The influence of low intake of $n-3$ fatty acids on platelets in elderly people. Atherosclerosis 147, 187-192.

33. Bechoua S, Dubois M, Dominguez Z, Goncalves A, Némoz G, Lagarde M \& Prigent AF (1999) Protective effect of docosahexaenoic acid against hydrogen peroxide-induced oxidative stress in human lymphocytes. Biochem Pharmacol 57, $1021-1030$.
34. Komatsu W, Ishihara K, Murata M, Saito H \& Shinohara K (2003) Docosahexaenoic acid suppresses nitric oxide production and inducible nitric oxide synthase expression in interferongamma plus lipopolysaccharide-stimulated murine macrophages by inhibiting the oxidative stress. Free Radic Biol Med 34, $1006-1016$

35. Lemaitre D, Véricel E, Polette A \& Lagarde M (1997) Effects of fatty acids on human platelet glutathione peroxidase: possible role of oxidative stress. Biochem Pharmacol 53, 479-486.

36. Joulain C, Prigent AF, Némoz G \& Lagarde M (1994) Increased glutathione peroxidase activity in human blood mononuclear cells upon in vitro incubation with $n-3$ fatty acids. Biochem Pharmacol 47, 1315-1323.

37. Leonardi F, Attorri L, Benedetto RD, Biase AD, Sanchez M, Tregno FP, Nardini M \& Salvati S (2007) Docosahexaenoic acid supplementation induces dose and time dependent oxidative changes in C6 glioma cells. Free Radic Res 41, 748-756.

38. Williams MS \& Kwon J (2004) T cell receptor stimulation, reactive oxygen species, and cell signaling. Free Radic Biol Med 37, 1144-1151. 